\title{
The pregnant Jehovah's Witness
}

\author{
N C Drew Department of Obstetrics and Gynaecology, Louise Margaret Maternity Hospital, \\ Aldershot, Hants
}

\section{Author's abstract}

The prospect of dealing with a rapidly and inexorably bleeding patient fills most medical practitioners with alarm. When that patient is a fehovah's Witness, the knowledge that a blood transfusion is likely to be refused turns that alarm into a state of acute anxiety and conflict. This state is further heightened when the patient is young and otherwise healthy-a situation found particularly in obstetric practice with the occurrence of anteand post-partum haemorrhage, and ectopic pregnancy.

In the last 25 years in England, Wales, Scotland and Northern Ireland, there has been one maternal death in which the refusal to accept a blood transfusion has been considered to be an avoidable factor. In this article I have attempted to identify the magnitude of the problem in obstetric practice and have sought to clarify the moral and legal aspects.

\section{Facts and figures}

There are about 75,000 active Jehovah's Witnesses in the British Isles (Watch Tower, January 1978, personal communication). The population of the British Isles is around 56 million, with a birth rate of 12.2 per thousand head of population. (Office of Population Censuses and Surveys, personal communication.) Assuming that the age and sex incidence of the Jehovah's Witness population follows that of the general population, it can be calculated that each year 900 to 950 babies will be born to parents who are Jehovah's Witnesses, and that a unit delivering 1,500 babies a year could expect to include two Jehovah's Witnesses in their figures.

From the maternal mortality statistics from 1952I975 (I) it can be seen that the percentage of deaths due entirely or in part to the effect of haemorrhage is small and decreasing ( 17 per cent $1952-54 ; 5$ per cent $1973-75)$. As the overall death rate is about 13 per 100,000 births, the death of a Jehovah's Witness, due to haemorrhage, might therefore be expected once a century. It should be remembered of course that many mothers might have died but for blood transfusion.

\section{Legal aspects}

The legal aspects of the treatment of Jehovah's Witnesses are clearly set out in the Medical Defence Union's handbook Consent to Treatment (2).

The Children and Young Persons Act 1969 (3) provides a method whereby a child (ie under 16 years old) may be removed from the custody of the parents. The Act requires that the applicant prove 'the child's proper development is being avoidably prevented or neglected, or its health is being inavoidably impaired or neglected, or that he is being illtreated and also that he is in need of care or control which he is unlikely to receive unless the Court makes an order'. It is possible however for persons under the age of 16 years to give consent, provided that they are aware of the situation and understand the consequences of their action (4). Evidence may be given to the Local Authorities too this effect, but it is an obviously slow and cumbersome method, possibly causing unacceptableon delay.

In 1967 , a Ministry of Health circular was issued advising the 'favoured procedure' (5). This letter was reinforced by a letter from the Home Office in I968 (6). The advice given was that the Hospital Authorities rely on the clinical judgment of the consultant concerned in the case. Before proceeding with a transfusion to a minor, the consultant-incharge was advised to obtain both the written support of a colleague that the patient was in urgent need of a blood transfusion and the written acknowledgment of the patient's parent or guardian that he or she refused to allow the patient to have a blood transfusion despite the life-threatening nature of the problem. Where it is considered that a baby would require an exchange transfusion after delivery, permission can be sought prior to delivery. The position regarding intrauterine transfusion is not clear; I am unaware of any reported cases where this has been contemplated.

A practitioner, when consulted by a Jehovah's Witness, must inform the patient that the help sought could entail the use of blood transfusion. The Witness will, of course, refuse blood (or renounce the Fellowship). The practitioner may then decide not to accept the patient for treatment and refer her elsewhere, or to accept the patient who is asked to sign a form refusing blood transfusion and accepting the possible consequences. It is wise to 
obtain a third party witness to this signature which should be countersigned by the practitioner.

When presented with a Jehovah's Witness dying from the effects of blood loss, the practitioner has to decide whether to ignore the patient's known abhorrence of blood transfusion and give blood, or to accept that blood cannot be given, and attempt resuscitation without it. It is apparent that blood is given to Witnesses without their consent; legally, however, the patient's wishes must be respected. The Secretary of the Medical Defence Union reiterated this point in a letter to the Practitioner in 1968 (7). A case was reported in 1969 in which a blood transfusion was given without permission, but legal action was not taken by the patient or her relatives. (Watch Tower, 1979, personal communication). Members of the Fellowship believe that there is little to be gained by prosecution in such cases.

\section{Alternatives to donor blood transfusion}

As it is now possible to take a patient's blood, freeze it and store it in liquid nitrogen, it had been hoped to be able to solve the problem of pregnant Jehovah's Witnesses by storing their blood in early pregnancy in order to be able to return it to them should the need arise. Unfortunately, this has proved to be unacceptable as Jehovah's teaching states that blood must not be 'taken' in any form. The foundation of this teaching is explained in the Jehovah's Witness pamphlet The Question of Blood (8), which makes interesting if somewhat repetitive reading.

It is, of course, possible to use plasma expanders alone as patients are able to cope well down to a haemoglobin level of about $6 \mathrm{gm} / \mathrm{dl}$. The use of hyperbaric oxygen therapy should also be considered if facilities exist. Research is continuing presently into the use of fluorocarbons as blood substitutes; indeed a mouse is living in America in a total fluorocarbon environment and fluorocarbons have been used during operations on humans, but they are not yet available for general use. The technique of binding pure haemoglobin on to a large molecular weight carrier is still in the research stage. With luck either or both of these blood substitutes will one day become readily available, thus eliminating the need for blood transfusion.

The ethical dilemma posed by Jehovah's Witnesses therefore continues to exist despite recent advances. When faced with this dilemma one must consider if it is ever defensible to ignore the patient's expressed desire not to have treatment, even though that refusal may result in continuing ill health or even death.

For a doctor (or anyone else) to force a patient to have treatment is both morally and legally wrong. The patient's right not to have treatment should be considered sacrosanct. In I967 the Secretary
Treasurer of the Canadian Medical Protective Association (9) stated 'It is an axiom of practice that nothing can be done to or for a patient without the patient's permission. Even though a doctor think that without treatment a patient may come to harm; without consent he may not administer the treaten ment considered necessary. A doctor is not Godo nor is he a dictator, and he may not impose treat ment against a patient's wishes.'

It is now becoming increasingly apparent in the United States that the right of competent indity viduals to refuse treatment is a very powerfue right (IO), which has the support of the law courts? although no court has yet gone so far as to say directly that there is an absolute right to refuse treatment.

Is there any way round this difficult problem? Can the patient's wishes be overridden, and if sosw should they be overridden? It is tempting to await the onset of unconsciousness (which may be the end result of the blood loss itself, or due to generab anaesthesia required for example to deliver the baby), and administer a blood transfusion without the patient's knowledge. What though is the purpose of deliberately deceiving the patient 3 It has to be admitted immediately that the patient' wishes are being ignored. In forcing treatment a conviction is being expressed that the doctor knowveo best and that the patient will be grateful when she has recovered. This is a selfish attitude and not gif whose validity has been borne out by experienees A Witness who has been in receipt of blood is likelyo to have to renounce the Fellowship; she may be rejected by her friends and even by her family, t尺 lead a life of guilt and remorse; a child made a ward of court can likewise be renounced by the family and end up in care.

If it is accepted that a patient has a prime righ. to refuse treatment, should it also be accepted that parents have a right to refuse treatment for theip children; furthermore, does a pregnant womas have a right to deny treatment to her unborn fetus

Children are not generally considered to be experienced enough to make reasoned decisions 3 especially when those decisions can affect their well being. Thus their views are not sought when if comes to accepting or refusing treatment such as. blood transfusion. Who, however, is competenf to make that decision? Is it the parents who might try and force their own, possibly injurious an narrow, views on an individual to whom they ares related by an accident of inheritance, or is it societs in general, whose less extreme views would pose sibly enable the child to survive until an age whes self-determination was possible. The price of survival could be very high, however, with the possibility of rejection of the child and breakup of the family but is probably preferable to the deatp of the child. 
A fetus compromised by Rhesus haemolytic disease will require delivery with or without exchange transfusion, or, if very severely affected in early pregnancy, will need intra-uterine transfusion. When delivered it can be given a transfusion using the legal process outlined above, but intrauterine transfusion would require the consent of the mother as she would have to submit herself to abdominal and uterine puncture. This of course she would refuse in the knowledge that blood was to be used. It may be that she would refuse the routine investigations, such as amniocentesis, if this was likely to lead to subsequent early delivery and exchange transfusion.

The alternatives to intra-uterine transfusion would be to deliver the child very early or to acquiesce to the mother's wishes knowing that the baby's chances of survival might be severely compromised. At present it is not possible to force a mother to co-operate (for example a mother may insist on smoking heavily in the face of overwhelming evidence of its injurious nature); it will require a test case on behalf of the unborn child to determine its rights as an individual before this question can be answered.

In practice therefore the answers are fairly straightforward. The right of an adult to refuse treatment is very strong and must be upheld, but the right of a parent to determine the treatment of his or her offspring is far weaker and adequate legal provisions exist to protect the child against potentially dangerous views. The rights of the fetus are as yet undetermined: fortunately severe Rhesus disease is becoming a rarity so it is unlikely that a problem such as that described will be encountered in the careers of most obstetricians.

\section{References}

(I) Report on confidential enquiries into maternal deaths in England and Wales (1962-1975) HMSO; London, 1979; Reprinted 1980,

(2) Medical Defence Union. Consent to treatment. H Burt and Son Ltd, Bedford, I974; ro-12.

(3) Children and Young Persons Act 1969. Para A Subsection One.

(4) Family Law Reform Act 1969. Section 8 (I) and 8 (3).

(5) Ministry of Health Circular 1967. F/P 9 IB.

(6) Home Office Letter HDC 63/1968/D2.

(7) Secretary of the Medical Defence Union. Correspondence Practitioner, 1968; 200: 314.

(8) Watch Tower Bible and Tract Society of Pennsylvania. Fehovah's Witnesses and the question of blood. Watch Tower Bible and Tract Society of New York Inc. International Bible Students Association, Brooklyn, New York, USA, 1977.

(9) Fisher T L. Consent for treatment. Canadian Medical Association fournal, 1967; 96: 98-99.

(Io) Elliot J. More support for refusing medical treatment. Fournal of American Medical Association 1980; 243: 506-507. 